\title{
mcr-1 in Carbapenemase-Producing Klebsiella pneumoniae in Hospitalized Patients, Portugal, 2016-2017
}

\section{Ana Constança Mendes, ${ }^{1}$ Ângela Novais, ${ }^{1}$ Joana Campos, Carla Rodrigues, Cláudia Santos, Patrícia Antunes, Helena Ramos, Luísa Peixe}

We describe a hospital-based outbreak caused by multidrugresistant, Klebsiella pneumoniae carbapenemase 3-producing, $m c r-1$-positive $K$. pneumoniae sequence type 45 in Portugal. $m c r-1$ was located in an IncX4 plasmid. Our data highlight the urgent need for systematic surveillance of $m c r-1$ to support adequate therapeutic choices in the nosocomial setting.

$\mathrm{I}^{\mathrm{n}}$ nfections with carbapenemase-producing Enterobacteriaceae (CPE), such as Klebsiella pneumoniae, have been increasing since 2011 in hospitalized patients in several countries in Europe, especially those with high resistance rates (https://ecdc.europa.eu/sites/portal/files/documents/ antibiotics-EARS-Net-summary-2016_0.pdf; https://ecdc. europa.eu/sites/portal/files/documents/AMR-surveillanceEurope-2016.pdf). The emergence of mobilized colistin resistance (MCR) genes is particularly concerning because colistin is being intensively used as a last resource antimicrobial drug for treating CPE infections $(1,2)$. In Europe, sporadic clinical CPE isolates with $m c r-1$ have been reported $(3,4)$. Because CPE has increased at an alarming pace in Portugal $(5,6)$, we evaluated the occurrence of $m c r-1$ among $\mathrm{CPE}$ isolated from patients admitted to Centro Hospitalar do Porto, a tertiary and university hospital in Porto, Portugal.

\section{The Study}

Using rectal swab specimens from 5,361 patients admitted to Centro Hospitalar do Porto during October 2015-July 2017, we screened for carbapenemase-positive isolates using Brilliance CRE Agar (Oxoid, Basingstoke, UK), Blue-carba test (7), and real-time PCR for carbapenemase genes (Xpert Carba-R; Cepheid, Sunnyvale, CA, USA) (Figure 1, panel A). We identified 283 patients with 359 CPE-positive samples available for further testing. Of the 359 isolates, 252 (75\% $\mathrm{K}$. pneumoniae-positive) were from patient fecal samples and

Author affiliations: Centro Hospitalar do Porto, Porto, Portugal

(A.C. Mendes, C. Santos, H. Ramos); Faculdade de Farmácia,

Universidade do Porto, Porto (Â. Novais, J. Campos,

C. Rodrigues, P. Antunes, L. Peixe); Faculdade de Ciências da

Nutrição e Alimentação, Universidade do Porto, Porto (P. Antunes)

DOI: https://doi.org/10.3201/eid2404.171787
107 (86\% K. pneumoniae-positive) were from other types of patient samples (e.g., blood, urine). We then screened these isolates for $m c r-1$, bla $a_{\mathrm{CTX}-\mathrm{M}-\mathrm{I}}$-like genes, and $b l a_{\mathrm{KPC}}$ using PCR and sequencing $(5,8,9)$. We determined the antimicrobial drug susceptibility profiles of the $m c r$-1-positive isolates by the broth microdilution method for colistin (http://www. eucast.org/fileadmin/src/media/PDFs/EUCAST_files/General_documents/Recommendations_for_MIC_determination_of_colistin_March_2016.pdf) and by disk diffusion for the other antimicrobial drugs using Clinical and Laboratory Standards Institute/European Committee on Antimicrobial Susceptibility Testing guidelines (http://www.eucast.org/). We evaluated clonal relatedness among $K$. pneumoniae isolates by multilocus sequence and wzi capsular typing (http:// bigsdb.pasteur.fr/perl/bigsdb/bigsdb.pl?db = pubmlst_klebsiella_seqdef_public) and assessed plasmid replicon content using PCR (5). We performed whole-genome sequencing with 2 isolates of the predominant $K$. pneumoniae clones by Hi Seq 2500 Sequencing System (Illumina Inc., San Diego, CA, USA) $(2 \times 150$ bp paired-ended reads, coverage $100 \times)$. We assembled reads de novo using SPAdes version 3.9.0 (http://cab.spbu.ru/software/spades/) and annotated contigs with Prokka (http://vicbioinformatics.com/). We used tools from the Center for Genomic Epidemiology (http://www. genomicepidemiology.org) to assess antimicrobial drug resistance genes and replicons and PLACNETw (https://castillo.dicom.unican.es/upload/) for plasmid reconstruction. We located $m c r-1$ in the IncX4 plasmid near the replication (pirF) and maintenance (parA) conserved regions by PCR and sequencing (Figure 2).

We identified 24 carbapenemase-producing and MCR-1-producing $K$. pneumoniae isolates from samples collected during September 2016-February 2017 from 16 hospitalized patients (Figure 1, panel B). Seventeen isolates were colonizers (i.e., bacteria of the patients' gastrointestinal tract), and 7 were from other parts of the body (3 urine, 2 blood, 2 other biologic fluids) (Table). We recovered 1-4 isolates/patient; 10 colonizing isolates were from intensive care units. Patients ( 9 men, 7 women) were 50-87 years of age, and their clinical history included prolonged hospitalization (median $47 \mathrm{~d}$, range 12-151 d); complicated conditions; and, for many, surgical interventions, immunosuppression, or previous antimicrobial drug

${ }^{1}$ These authors contributed equally to this article. 
use (usually $\beta$-lactams) favoring infection or colonization by multidrug-resistant (MDR) $m c r-1$-positive strains (10). Fecal samples were negative for CPE at admission (14/16 patients screened) and for a median of 15 (range 3-94) days

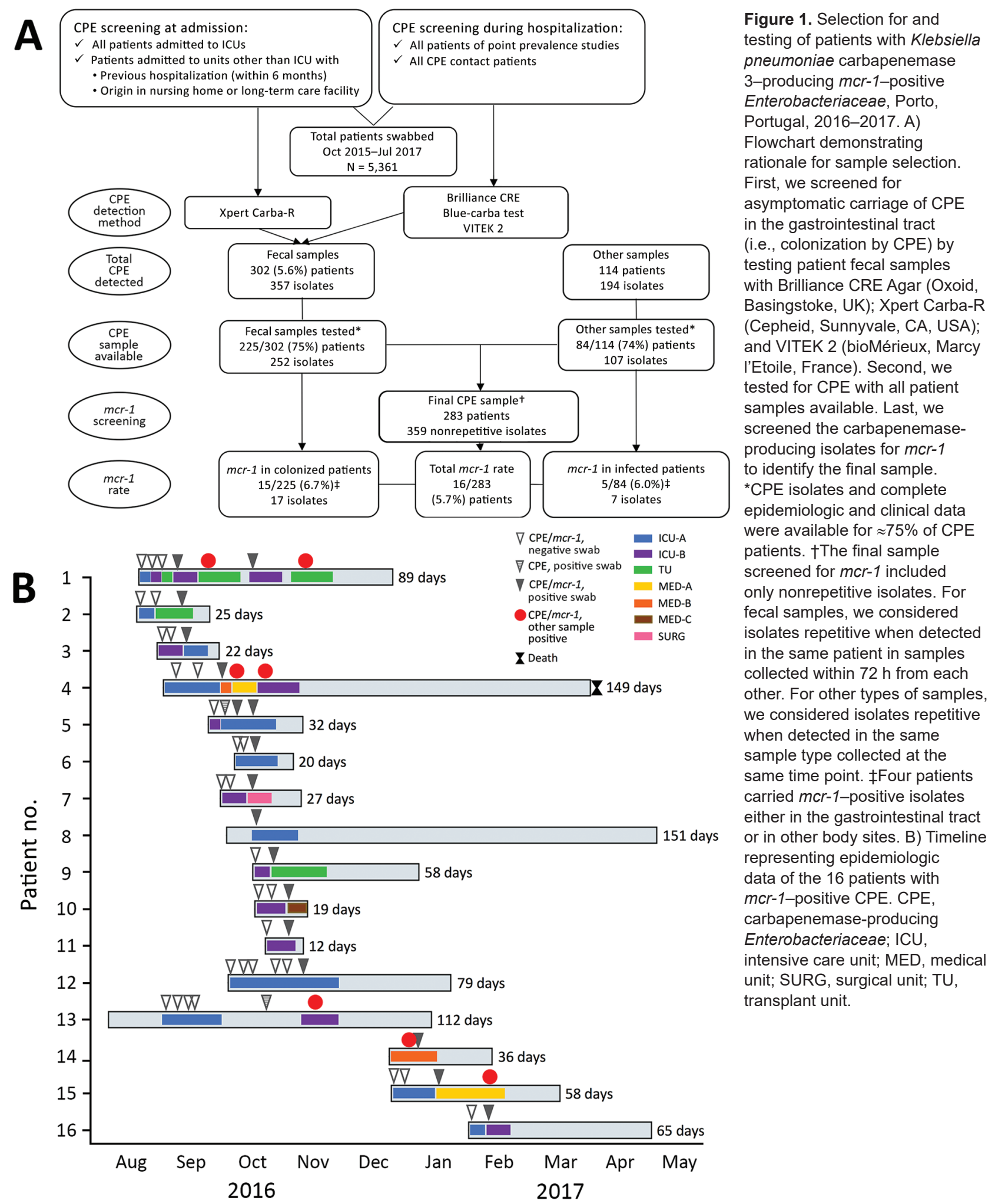

after admission (Figure 1, panel B). Five patients had 1 or 2 extraintestinal infections with an MCR-1-producing isolate, sometimes with an isolate identical to one previously detected in their gastrointestinal tract. 3-producing mcr-1-positive Enterobacteriaceae, Porto, rationale for sample selection. First, we screened for testing patient fecal samples (Cepheid, Sunnyvale, CA, USA); and VITEK 2 (bioMérieux, Marcy l'Etoile, France). Second, we tested for CPE with all patient samples available. Last, we epidemiologic and clinical data were available for $\approx 75 \%$ of CPE only nonrepetitive isolates. For ecal samples, we considered isolates repetitive when detected repetitive when detected in the same either in the gastrointestinal tract or in other body sites. B) Timeline representing epidemiologic carbapenemase-producing Enterobacteriaceae; ICU, unit; SURG, surgical unit; TU transplant unit. (i.e colonization by CPE) by 


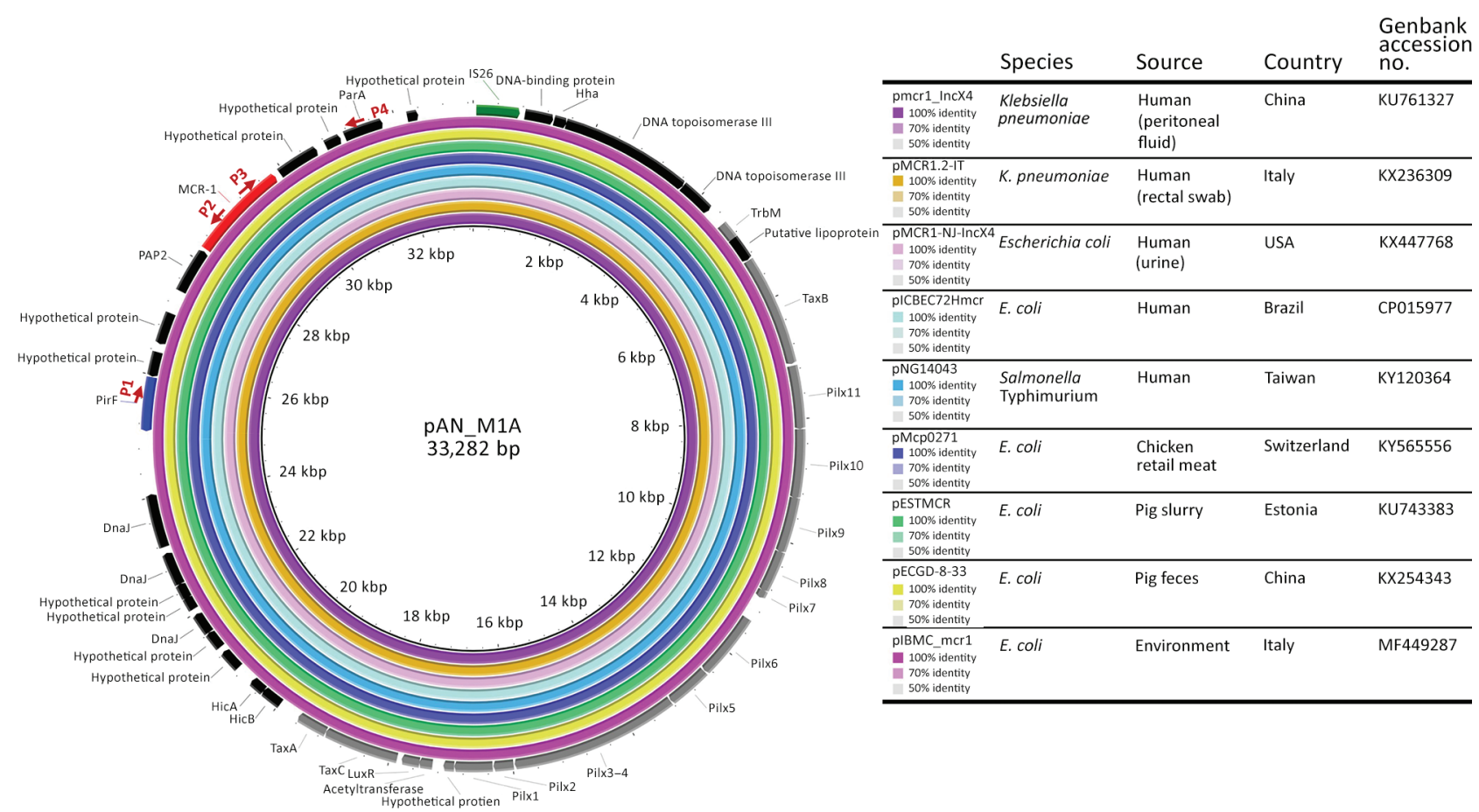

Figure 2. Alignment of representative mcr-1-harboring IncX4 plasmids from different isolation sources and geographic regions. The mcr-1-harboring plasmid pAN_M1A was used as a reference plasmid. The outermost circle is an annotation of the reference plasmid and shows the direction of transcriptional open-reading frames. The pil loci and other genes (gray), replication-associated genes (dark blue), antimicrobial drug resistance gene (red), and insertion sequence (green) are indicated. The strategy for PCR mapping of $m c r-1-$ carrying plasmids is indicated by red arrows. Primer P1 targets pirF, P2 mcr-1 (3.3 kb), P3 mcr-1, and P4 parA (2.1 kb).

Colistin use and travel abroad were not recorded for any patient before $m c r-1$ detection; however, 5 of the 16 patients had been hospitalized in the previous 6 months. Patients were treated for CPE infection with colistin and a carbapenem, which was supplemented with fosfomycin, tigecycline, or piperacillin/tazobactam depending on clinical criteria. We missed colistin resistance initially because we used conventional antimicrobial susceptibility tests VITEK 2 (bioMérieux, Marcy l'Etoile, France) and Etest (bioMérieux), which are unreliable at detecting colistin resistance. Adequate colistin resistance monitoring (http://www.eucast.org/fileadmin/src/media/PDFs/EUCAST_files/General_documents/Recommendations_for_MIC_determination_of_colistin_March_2016.pdf) and $m c r-1$ screening for CPE isolates was implemented in July 2017.

Isolates carrying $m c r-1.1$ were resistant to colistin (MIC 4-8 $\mathrm{mg} / \mathrm{L}$ ), produced $K$. pneumoniae carbapenemase 3 (KPC-3), and most (79\%) produced CTX-M-15 $\beta$-lactamase. Besides $100 \%$ resistance to third and fourth generation cephalosporins and monobactams, K. pneumoniae isolates were also frequently resistant to nalidixic acid (100\%), ciprofloxacin (96\%), tigecycline (96\%), tetracycline $(92 \%)$, tobramycin $(88 \%)$, gentamicin $(88 \%)$, fosfomycin (83\%), trimethoprim/sulfamethoxazole (79\%), and chloramphenicol (67\%) (Table). All isolates were susceptible to amikacin (which was contraindicated for some patients because of renal insufficiency) and ceftazidime/avibactam (which was not available).

All but $1 \mathrm{~K}$. pneumoniae isolate belonged to sequence type (ST) 45 and carried wzi101/K24, a clone that has been infrequently detected among clinical MDR K. pneumoniae isolates in Portugal $(5,6)$ but has circulated among KPC-3 producers (without $m c r-1$ ) during the same period (L. Peixe, unpub. data). We detected 1 mcr-1-positive K. pneumoniae (capsular type KL122) ST1112 isolate from the pus of an abdominal wall abscess in a patient having $m c r-1-$ positive ST45 in previously collected fecal and urine samples (Table). The 2 whole-genome-sequenced $K$. pneumoniae ST45 isolates had genes encoding resistance to aminoglycosides [aac(6')Ib-cr,aac(3)-IIa]; $\beta$-lactams ( bla $_{\mathrm{KPC}-3}$, $\left.b l a_{\mathrm{SHV}-1}, b l a_{\text {OXA-1 }}\right)$, fluoroquinolones [qnrB66, aac (6') Ibcr,oqxAB], and other antimicrobial drugs [catB4,tet(A)]; 1 of the 2 isolates possessed additional genes $a p h(4)-I b$, strAB, bla ${ }_{\mathrm{TEM}-1 \mathrm{~B}}, b l a_{\mathrm{CTX}-\mathrm{M}-15}$, catAl, sul2, and dfrA14.

In all $m c r-1-$ positive isolates, the gene was located in an IncX4-type plasmid (Figure 2). Comparative genomics revealed that this plasmid (pAN_M1A) is circulating among diverse hosts (humans, pig, poultry) and the environment in many different countries, including Portugal (11). We identified $b l a_{\mathrm{KPC}-3}$ in a Tn4401d isoform in an $\approx 58-\mathrm{kb}$ 
Table. Demographic and epidemiologic data for 16 patients with Klebsiella pneumoniae isolates producing KPC-3 and MCR-1, Porto, Portugal, 2016-2017*

\begin{tabular}{|c|c|c|c|c|c|c|}
\hline $\begin{array}{l}\text { Patient } \\
\text { no. }\end{array}$ & $\begin{array}{c}\text { Patient } \\
\text { age, y/sex }\end{array}$ & MLST & $\begin{array}{l}\text { Date of } \\
\text { isolation }\end{array}$ & Unit & Specimen type & Antimicrobial drug resistance profile of non- $\beta$-lactams $\dagger$ \\
\hline \multirow[t]{4}{*}{1} & \multirow[t]{4}{*}{$50 / \mathrm{M}$} & ST45 & 2016 Sep 10 & ICU-B & Rectal swab & $\begin{array}{c}\text { GEN, KAN, NET, TOB, STR, TET, MIN, TGC, FOT, } \\
\text { TMP, SXT, NAL, CIP }\end{array}$ \\
\hline & & ST45 & 2016 Sep 23 & TU & Peritoneal fluid & $\begin{array}{l}\text { GEN, KAN, NET, TOB, STR, TET, MIN, TGC, FOT, } \\
\text { TMP, SXT, CAM, NAL, CIP }\end{array}$ \\
\hline & & ST45 & 2016 Oct 14 & ICU-B & Rectal swab & MIN, FOT, TET, TGC, SXT, CAM, NAL, CIP \\
\hline & & ST45 & 2016 Nov 8 & TU & Urine & $\begin{array}{c}\text { GEN, KAN, NET, TOB, STR, TET, MIN, TGC, FOT, } \\
\text { TMP, SXT, NAL, CIP }\end{array}$ \\
\hline 2 & $55 / \mathrm{M}$ & ST45 & 2016 Sep 11 & TU & Rectal swab & $\begin{array}{c}\text { GEN, NET, TOB, STR, TET, MIN, TGC, FOT, TMP, } \\
\text { SXT, CAM, NAL, CIP }\end{array}$ \\
\hline 3 & $58 / F$ & ST45 & 2016 Sep 12 & ICU-A & Rectal swab & $\begin{array}{l}\text { GEN, KAN, NET, TOB, STR, TET, MIN, TGC, FOT, } \\
\text { TMP, SXT, CAM, NAL, CIP }\end{array}$ \\
\hline \multirow[t]{3}{*}{4} & \multirow[t]{3}{*}{$73 / F$} & ST45 & 2016 Oct 1 & MED-B & Rectal swab & $\begin{array}{c}\text { GEN, KAN, NET, TOB, STR, TET, MIN, TGC, FOT, } \\
\text { TMP, SXT, CAM, NAL, CIP }\end{array}$ \\
\hline & & ST45 & 2016 Oct 4 & MED-A & Urine & $\begin{array}{l}\text { GEN, KAN, NET, TOB, STR, TET, MIN, TGC, FOT, } \\
\text { TMP, SXT, NAL, CIP }\end{array}$ \\
\hline & & ST1112 & 2016 Oct 22 & ICU-B & Pus & TET, MIN, FOT, TMP, CAM, NAL, CIP \\
\hline \multirow[t]{2}{*}{5} & \multirow[t]{2}{*}{ 72/M } & ST45 & 2016 Oct 10 & ICU-A & Rectal swab & $\begin{array}{c}\text { GEN, KAN, NET, TOB, TET, MIN, TGC, FOT, CAM, } \\
\text { NAL, CIP }\end{array}$ \\
\hline & & ST45‡ & 2016 Oct 14 & ICU-A & Rectal swab & $\begin{array}{c}\text { GEN, KAN, NET, TOB, TET, MIN, TGC, FOT, CAM, } \\
\text { NAL, CIP }\end{array}$ \\
\hline 6 & 75/M & ST45 & 2016 Oct 14 & ICU-A & Rectal swab & $\begin{array}{c}\text { GEN, KAN, NET, TOB, STR, TET, MIN, TGC, FOT, } \\
\text { TMP, SXT, CAM, NAL, CIP }\end{array}$ \\
\hline 7 & 68/M & ST45 & 2016 Oct 14 & SURG & Rectal swab & $\begin{array}{l}\text { GEN, KAN, TOB, STR, TET, MIN, TGC, FOT, TMP, } \\
\text { SXT, NAL, CIP }\end{array}$ \\
\hline 8 & $78 / F$ & ST45 & 2016 Oct 15 & ICU-A & Rectal swab & $\begin{array}{l}\text { GEN, KAN, NET, TOB, STR, TET, MIN, TGC, FOT, } \\
\text { TMP, SXT, CAM, NAL, CIP }\end{array}$ \\
\hline 9 & $58 / \mathrm{M}$ & ST45 & 2016 Oct 25 & TU & Rectal swab & $\begin{array}{l}\text { GEN, KAN, NET, TOB, STR, TET, MIN, TGC, FOT, } \\
\text { TMP, SXT, CAM, NAL, CIP }\end{array}$ \\
\hline 10 & $51 / \mathrm{M}$ & ST45 & 2016 Nov 1 & MED-C & Rectal swab & $\begin{array}{l}\text { KAN, NET, TOB, STR, TET, MIN, TGC, TMP, SXT, } \\
\text { CAM, NAL, CIP }\end{array}$ \\
\hline 11 & $87 / F$ & ST45‡ & 2016 Nov 1 & ICU-B & Rectal swab & $\begin{array}{l}\text { GEN, KAN, STR, TET, MIN, TGC, FOT, TMP, SXT, } \\
\text { NAL, CIP }\end{array}$ \\
\hline 12 & $67 / \mathrm{F}$ & ST45 & 2016 Nov 7 & ICU-A & Rectal swab & GEN, TOB, STR, MIN, TGC, FOT, CAM, NAL, CIP \\
\hline 13 & $57 / \mathrm{M}$ & ST45 & 2016 Nov 7 & ICU-B & Blood & GEN, NET, TOB, STR, TET, MIN, TGC, FOT, CAM, NA \\
\hline \multirow[t]{2}{*}{14} & \multirow[t]{2}{*}{$76 / \mathrm{M}$} & ST45 & 2016 Dec 30 & MED-B & Blood & $\begin{array}{l}\text { GEN, KAN, NET, TOB, STR, TET, MIN, TGC, FOT, } \\
\text { TMP, SXT, CAM, NAL, CIP }\end{array}$ \\
\hline & & ST45 & 2017 Jan 2 & MED-B & Rectal swab & $\begin{array}{l}\text { GEN, KAN, NET, TOB, STR, TET, MIN, TGC, TMP, } \\
\text { SXT, NAL, CIP }\end{array}$ \\
\hline \multirow[t]{2}{*}{15} & \multirow[t]{2}{*}{$85 / F$} & ST45 & 2017 Jan 16 & MED-A & Rectal swab & $\begin{array}{l}\text { GEN, KAN, NET, TOB, STR, TET, MIN, TGC, FOT, } \\
\text { TMP, SXT, CAM, NAL, CIP }\end{array}$ \\
\hline & & ST45 & 2017 Feb 7 & MED-A & Urine & GEN, NET, TOB, STR, TGC, TMP, SXT, NAL, CIP \\
\hline 16 & $63 / F$ & ST45 & 2017 Feb 7 & ICU-B & Rectal swab & $\begin{array}{r}\text { GEN, KAN, NET, TOB, STR, TET, MIN, TGC, TMP, } \\
\text { SXT, NAL, CIP }\end{array}$ \\
\hline $\begin{array}{l}\text { NET, n } \\
\text { TOB, to } \\
\text { tWe co }\end{array}$ & $\begin{array}{l}\text { in; SURC } \\
\text { incin; TMF } \\
\text { red isolat } \\
\text { ected for } \\
\end{array}$ & $\begin{array}{l}\text { IP, cipr } \\
\text { mobili } \\
\text { rgical u } \\
\text { nethop } \\
\text { ith inte } \\
\text { e-geno } \\
\end{array}$ & $\begin{array}{l}\text { listin resistar } \\
\text {, sequence t transplant } \\
\text { te susceptib } \\
\text { quencing. }\end{array}$ & st & $\begin{array}{l}\text { mycin; SXT, tr } \\
\text { myt. }\end{array}$ & $\begin{array}{l}\text { ive care unit; KAN, kanamycin; KPC-3, K. pneumoniae } \\
\text { cline; MLST, multilocus sequence type; NAL, nalidixic acid; } \\
\text { prim/sulfamethoxazole; TET, tetracycline; TGC, tigecycline; }\end{array}$ \\
\hline
\end{tabular}

IncN-ST15 plasmid, a minority platform in our previous survey (5); bla $a_{\text {CTX-M-15 }}$ was associated with multireplicon plasmid IncFII $_{\mathrm{K}}$-FIA-FIB. We deposited this whole-genome shotgun project at DDBJ/European Nucleotide Archive/GenBank under accession no. PEHI00000000.

We found that $5.7 \%(16 / 283)$ of hospitalized patients had gastrointestinal tracts colonized with $m c r-1$-positive $\mathrm{CPE}$, and in $1.8 \%(5 / 283)$ of these patients, an infection developed; these rates are comparable with those reported in China (up to $6.2 \%$ for fecal colonization, $1 \%$ for infections) $(10,12)$. In China, only 1 outbreak involving mcr-1-carrying clinical isolates has been reported (13), and in Europe, a low occurrence $(<1 \%)$ and sporadic clinical cases have been reported $(3,4)$. Colistin is a critical last resource antimicrobial drug; prolonged carriage of $\mathrm{mcr}-1-$ positive MDR strains (especially by patients at discharge) represents a risk for subsequent infections and dissemination to other Enterobacteriaceae species. Of note, identifying CPE asymptomatic carriers at discharge is a practice recommended in Portugal, though not mandatory. 
Considering the absence of CPE at admission, nosocomial acquisition and in-hospital dissemination of KPC-3producing strains carrying $\mathrm{mcr}-1$ is plausible; however, we cannot rule out that other K. pneumoniae lineages or Escherichia coli might have been the source of $m c r-1$. Although the prevalence of colonization of humans by $\mathrm{mcr}$-1-positive strains is unknown in Portugal, previous detection of $\mathrm{mcr}-1$ in livestock, such as K. pneumoniae ST45 in pigs, suggests transmission through the food chain and wider dispersion of MCR-1-producing Enterobacteriaceae $(8,11,14,15)$.

\section{Conclusions}

We report the emergence of $m c r-1$ in MDR KPC-3-producing $K$. pneumoniae associated with an unnoticed outbreak. High rates of CPE and colistin use $(2,5,6)$ together with an ongoing community-based dissemination of $\mathrm{mcr}$ forebodes of future similar events. Our data stress the need for a concerted action involving different professionals and healthcare institutions to monitor and contain the spread of $m c r$ across human and veterinary niches, the food chain, and the environment.

This work received financial support from the European Union (FEDER funds POCI/01/0145/FEDER/007728) and National Funds (Fundação para a Ciência e Tecnologia and Ministério da Educação e Ciência) under the partnership agreement PT2020 UID/MULTI/04378/2013. Fellowship support was provided by Fundação para a Ciência e Tecnologia through Programa Operacional Capital Humano to Â.N. (grant no. SFRH/ BPD/104927/2014), to J.C. (grant no. SFRH/BD/93091/2013), and to C.R. (grant no. SFRH/BD/84341/2012).

\section{About the Author}

Ms. Mendes is a biomedical scientist in the Microbiology Service and Molecular Biology Unit at Centro Hospitalar do Porto (Porto, Portugal). She is currently pursuing her doctorate, with research interests in molecular epidemiology of multidrugresistant Enterobacteriaceae.

\section{References}

1. Liu YY, Wang Y, Walsh TR, Yi LX, Zhang R, Spencer J, et al. Emergence of plasmid-mediated colistin resistance mechanism MCR-1 in animals and human beings in China: a microbiological and molecular biological study. Lancet Infect Dis. 2016;16:161-8. http://dx.doi.org/10.1016/S1473-3099(15)00424-7

2. European Centre for Disease Prevention and Control; European Food Safety Authority; European Medicines Agency. ECDC/EFSA/ EMA second joint report on the integrated analysis of the consumption of antimicrobial agents and occurrence of antimicrobial resistance in bacteria from humans and food-producing animalsJoint Interagency Antimicrobial Consumption and Resistance Analysis (JIACRA) Report. EFSA Journal. 2017;15:4872.

3. Huang TD, Bogaerts P, Berhin C, Hoebeke M, Bauraing C, Glupczynski Y. Increasing proportion of carbapenemase-producing Enterobacteriaceae and emergence of a MCR-1 producer through a multicentric study among hospital-based and private laboratories in Belgium from September to November 2015. Euro
Surveill. 2017;22:30530. http://dx.doi.org/10.2807/1560-7917. ES.2017.22.19.30530

4. Di Pilato V, Arena F, Tascini C, Cannatelli A, Henrici De Angelis L, Fortunato S, et al. $m c r-1.2$, a new $m c r$ variant carried on a transferable plasmid from a colistin-resistant KPC carbapenemase-producing Klebsiella pneumoniae strain of sequence type 512. Antimicrob Agents Chemother. 2016;60:5612-5. http://dx.doi.org/10.1128/AAC.01075-16

5. Rodrigues C, Bavlovič J, Machado E, Amorim J, Peixe L, Novais Â. KPC-3-producing Klebsiella pneumoniae in Portugal linked to previously circulating non-CG258 lineages and uncommon genetic platforms (Tn4401d-IncFIA and Tn4401d-IncN). Front Microbiol. 2016;7:1000. http://dx.doi.org/10.3389/fmicb.2016.01000

6. Manageiro V, Ferreira E, Almeida J, Barbosa S, Simões C, Bonomo RA, et al.; Antibiotic Resistance Surveillance Program in Portugal. Predominance of KPC-3 in a survey for carbapenemase-producing Enterobacteriaceae in Portugal. Antimicrob Agents Chemother. 2015;59:3588-92. http://dx.doi.org/10.1128/AAC.05065-14

7. Pires J, Novais A, Peixe L. Blue-carba, an easy biochemical test for detection of diverse carbapenemase producers directly from bacterial cultures. J Clin Microbiol. 2013;51:4281-3. http://dx.doi.org/10.1128/JCM.01634-13

8. Campos J, Cristino L, Peixe L, Antunes P. MCR-1 in multidrugresistant and copper-tolerant clinically relevant Salmonella 1,4,[5],12:i:- and $S$. Rissen clones in Portugal, 2011 to 2015. Euro Surveill. 2016;21:30270. http://dx.doi.org/10.2807/1560-7917. ES.2016.21.26.30270

9. Falgenhauer L, Waezsada S-E, Yao Y, Imirzalioglu C, Käsbohrer A, Roesler U, et al.; RESET consortium. Colistin resistance gene $m c r-1$ in extended-spectrum $\beta$-lactamase-producing and carbapenemase-producing gram-negative bacteria in Germany. Lancet Infect Dis. 2016;16:282-3. http://dx.doi.org/10.1016/ S1473-3099(16)00009-8

10. Wang Y, Tian GB, Zhang R, Shen Y, Tyrrell JM, Huang X, et al. Prevalence, risk factors, outcomes, and molecular epidemiology of $m c r$-1-positive Enterobacteriaceae in patients and healthy adults from China: an epidemiological and clinical study. Lancet Infect Dis. 2017;17:390-9. http://dx.doi.org/10.1016/ S1473-3099(16)30527-8

11. Tacão M, Tavares RDS, Teixeira P, Roxo I, Ramalheira E, Ferreira S, et al. $m c r-1$ and $b l a_{\mathrm{KPC}-3}$ in Escherichia coli sequence type 744 after meropenem and colistin therapy, Portugal. Emerg Infect Dis. 2017;23:1419-21. http://dx.doi.org/10.3201/eid2308.170162

12. Zhong LL, Phan HTT, Shen C, Doris-Vihta K, Sheppard AE, Huang X, et al. High rates of human fecal carriage of $m c r-1-$ positive multidrug-resistant Enterobacteriaceae emerge in China in association with successful plasmid families. Clin Infect Dis. 2017. http://dx.doi.org/10.1093/cid/cix885

13. Tian GB, Doi Y, Shen J, Walsh TR, Wang Y, Zhang R, et al. MCR-1-producing Klebsiella pneumoniae outbreak in China. Lancet Infect Dis. 2017;17:577. http://dx.doi.org/10.1016/ S1473-3099(17)30266-9

14. Kieffer N, Aires-de-Sousa M, Nordmann P, Poirel L. High rate of MCR-1-producing Escherichia coli and Klebsiella pneumoniae among pigs, Portugal. Emerg Infect Dis. 2017;23:2023-9. http://dx.doi.org/10.3201/eid2312.170883

15. Manageiro V, Clemente L, Graça R, Correia I, Albuquerque $\mathrm{T}$, Ferreira E, et al. New insights into resistance to colistin and third-generation cephalosporins of Escherichia coli in poultry, Portugal: novel bla $a_{\mathrm{CTX}-\mathrm{M}-166}$ and $b l a_{\mathrm{ESAC}}$ genes. Int J Food Microbiol. 2017;263:67-73. http://dx.doi.org/10.1016/j.ijfoodmicro.2017.10.007

Address for correspondence: Luísa Peixe, UCIBIO, Laboratório de Microbiologia, Faculdade de Farmácia, Universidade do Porto, Rua Jorge de Viterbo Ferreira, n. 228, 4050-313 Porto, Portugal; email: 1peixe@ff.up.pt 